\title{
FEIRANTE EMPREENDEDOR: EFETIVAÇÃO DOS DIREITOS FUNDAMENTAIS À IGUALDADE DE GÊNERO ENTRE HOMENS E MULHERES
}

\begin{abstract}
CAVALCANTE, L.C. ${ }^{1}$; FERREIRA, K.S. ${ }^{2}$ \& MOTA, S.H.M. ${ }^{3}$
1Professora da Faculdade de Economia, Administração, Atuária, Contabilidade e Secretariado Executivo, Universidade Federal do Ceará, vinculada ao Departamento de Ciências Contábeis. Doutora em Sociologia pela Universidade Federal do Ceará (2012). Mestre em Direito Constitucional e Teoria do Estado pela Universidade de Fortaleza (2007). Graduada em Direito pela Universidade de Fortaleza (2000). Email: laracapelo@ @otmail.com; ${ }^{2}$ Professora Adjunta da Universidade Federal do Ceará no Departamento de Administração. Doutora em Educação Brasileira pela Universidade Federal do Ceará (2013). Mestre em Direito Público (Ordem Jurídica Constitucional) pela Universidade Federal do Ceará (2004). Graduada em Direito pela Universidade Federal do Ceará (2000) E-mail: kilviasf@yahoo.com.br; ${ }^{3}$ Graduando de Direito da Universidade Federal do Ceará. Graduado em Tecnologia de Gestão Financeira pela Faculdade Ateneu (2015). Email: saviohenrique.mm@gmail.com.
\end{abstract}

DOI: https://doi.org/10.32356/exta.v2.n18.33544 - Artigo submetido em 02/09/2018

\section{RESUMO}

O trabalho objetiva compreender a visão nativa dos feirantes que atuam no comércio de Rua em Fortaleza, nos bairros da cidade 2000 e na Praia do Futuro, quanto à efetivação do direito fundamental à igualdade nas relações de trabalho. A metodologia utilizada pode ser caracterizada como descritiva e exploratória, com método dedutivo e abordagem quantitativa e qualitativa acerca dos direitos fundamentais relacionados ao princípio da igualdade de gênero, objetivando-se compreender o ponto de vista do feirante conforme sua realidade. Por conseguinte, os resultados evidenciaram uma desigualdade de tratamento nas relações de trabalho entre homens e mulheres, além de uma carência na efetivação dos direitos fundamentais dos feirantes, tais como um meio ambiente digno de trabalho. Além disso, verificou-se que a predominância do machismo é um obstáculo que dificultam o acesso de mulheres feirantes atuarem no setor mais rentável das feiras. Os entrevistados ainda possuem uma visão conservadora quanto ao princípio da igualdade de gênero, tendo em vista que eles se limitam apenas ao labor realizado por ambos, e não aos benefícios proporcionados por suas atividades, bem como a capacidade das mulheres de também gerir negócios.

PALAVRAS-CHAVE: Feira móvel. Direitos Fundamentais. Igualdade de Gênero. Relações de Trabalho.

\section{ENTERPRISING MARKETER: EFFECTIVENESS OF FUNDAMENTAL RIGHTS TO GENDER EQUALITY BETWEEN MEN AND WOMEN}

\begin{abstract}
The objective of this work is to understand the native view of street traders who work in the street trade in Fortaleza, in the neighborhoods of the city 2000 and in Praia do Futuro, regarding the realization of the fundamental right to equality in labor relations. The methodology used can be characterized as descriptive and exploratory, with deductive method and quantitative and qualitative approach to fundamental rights related to the principle of gender equality. aiming to understand the marketer's point of view according to his reality. Consequently, the results showed an unequal treatment in the labor relations
\end{abstract}

between men and women, as well as a lack in the realization of the fair rights of the fair owners, such as a decent work environment. In addition, it was found that the predominance of machismo is an obstacle that hinder the access of fairground women to operate in the most profitable sector of fairs. Respondents still have a conservative view of the principle of gender equality, as they are limited only to the work done by both, and not to the benefits provided by their activities, as well as the capacity of women of manage business. 


\section{INTRODUÇÃO}

A feira tem como característica muito notória uma aglomeração de pessoas em um lugar específico para executar trocas e vendas de mercadorias. As feiras livres começaram a ganhar mais destaque nas Cruzadas (XI - XIII), porquanto nesse século as atividades tinham que atender as necessidades dos viajantes, as quais, com o decorrer do tempo, foram se diversificando, dispondo de grande relevância no que tange ao reconhecimento da atividade do comercio nas vilas e aldeias, bem como a promoção da comunicação e da interação de diversos povos.

Este trabalho tem como campo empírico de incidência de pesquisa as feiras que ocorrem nos bairros Cidade 2000 às sextas-feiras, de 6hs às 15hs, e na Praia do Futuro aos sábados em Fortaleza, de $6 \mathrm{hs}$ às $15 \mathrm{hs}$ - com a venda de produtos que vêm diretamente das Centrais de Abastecimento do Ceará S.A (Ceasa/CE) - atraem centenas de consumidores semanalmente. Há uma pluralidade de produtos ofertados nas barracas instaladas nas feiras dos bairros citados, como frutas, verduras e legumes, além de roupas, eletrônicos, ou com vendedores ambulantes que se instalam à margem da feira dispondo do movimento para estender suas mercadorias usadas, seja para venda ou troca, como roupas usadas, eletrodomésticos e ferramentas de construção.

A presente pesquisa foi desenvolvida a partir de estudos e ações realizadas pelo projeto de extensão "FEIRANTE EMPREENDE: Tecnologia da Informação, Desenvolvimento Humano e Crescimento Econômico no Comércio de Rua”. O referido projeto extensionista tem por objetivo proporcionar desenvolvimento humano e crescimento econômico aos feirantes buscando transmitir conhecimentos múltiplos e informações necessárias às suas atividades empresariais e laborais, informando-lhes sobre seus direitos fundamentais enquanto cidadãos, práticas contábil de organização e formalização da sua atividade empresarial (controle dos seus custos; elaboração de um plano de negócios; formalização; cumprimento de obrigações tributárias e previdenciárias; entre outras).

Nessa perspectiva, a pesquisa tem como objetivo geral compreender a visão nativa dos feirantes que atuam no comércio de rua que ocorre nos bairros da cidade 2000 e na Praia do Futuro, cidade de Fortaleza, no Estado do Ceará, quanto à efetivação do direito fundamental à igualdade nas relações de trabalho entre homens e mulheres. Procura-se, assim, responder à seguinte questão: Como se dá a efetivação do direito fundamental à igualdade entre homens e mulheres nas relações de trabalho nas feiras dos bairros Cidade 2000 e Praia do Futuro? 
A pesquisa traz como objetivos específicos: (1) descrever a realidade social de trabalho dos feirantes que atuam nos citados bairros; (2) discorrer acerca dos direitos fundamentais previstos na Constituição Federal de 1988 que são aplicáveis a realidade das feiras, dando ênfase no princípio da igualdade de gênero entre homens e mulheres; (3) Compreender e apresentar a visão nativa dos feirantes acerca da efetivação dos direitos fundamentais à igualdade de gênero nas relações de trabalho entre homens e mulheres; (4) Disseminar o conhecimento jurídico acerca dos direitos fundamentais dos feirantes por meio de diálogos em visitas semanais às feiras.

A metodologia utilizada pode ser caracterizada como descritiva e exploratória, com método dedutivo e abordagem quantitativa e qualitativa acerca dos direitos fundamentais relacionados ao princípio da igualdade de gênero, objetivando-se, por meio de uma observação participante, compreender e apresentar a visão nativa dos feirantes quanto à efetivação dos direitos fundamentais à igualdade nas relações de trabalho entre homens e mulheres, isto é, o ponto vista do feirante consoante a sua realidade de trabalho.

Entende-se sobre visão nativa o mesmo sentindo atribuído por Malinowski (1978, p. 33):

"[...] esse objetivo é de apreender o ponto de vista dos nativos, seu relacionamento com a vida, sua visão de seu mundo. É nossa tarefa estudar o homem e devemos, portanto, estudar tudo aquilo que mais intimamente lhe diz respeito, ou seja, o domínio que a vida exerce sobre ele".

O trabalho é de grande relevância para o âmbito jurídico, social e político, uma vez que busca disseminar conhecimento aos feirantes, especialmente aos feirantes do sexo feminino, acerca dos seus direitos fundamentais à igualdade de gênero nas relações de trabalho. Sem falar que os aspectos abordados podem trazer uma reflexão acerca dos caminhos a serem traçados para se alcançar políticas públicas que possam atenuar o contexto de desigualdade e de informalidade dos feirantes.

\section{CONCEPÇÕES JURÍDICAS: DO DIREITO FUNDAMENTAL À IGUALDADE DE GÊEERO ENTRE HOMENS E MULHERES}

Historicamente, fala-se em direitos que pretendem garantir a liberdade e a dignidade do homem, isto é, direitos inalienáveis, os quais não podem ser suprimidos. Na época clássica, como ocorreu na tragédia grega de Sófocles em 427 a.C (a terceira peça de uma sequência de três tratando do ciclo tebano), Antígona já contestava o poder de Creonte, alegando haver um poder superior (leis naturais) de origem divina de ordem universal acima das leis do rei 
(SEGUNDO, 2009). No entanto, a lei escrita, só vem ser positivada em tempos mais recentes, com influência da corrente do positivismo.

\subsection{Direito Fundamental x Direitos Humanos}

Antes de versar sobre os Direitos Fundamentais no ordenamento jurídico brasileiro, cabe explicitar as distinções entre Direitos Humanos e Direitos Fundamentais, visto que esses termos são comumente utilizados como sinônimos. Para Paulo Bonavides (2010) os direitos fundamentais são os que o ordenamento jurídico vigente estabelece como tal, enquanto os Direitos Humanos, conhecidos também como direitos do homem e da liberdade, são caracterizados como um direito sagrado, natural, intransmissível e imprescritível.

Entende-se que direito humano trata-se de um direito preexistente, nato do homem, que não encontra limites no tempo e no espaço posto que não está vinculado à positivação particular de um determinado ordenamento jurídico, pois ocupa uma posição natural, antes do Estado. Já a expressão direitos fundamentais traduz a ideia de positivação dos direitos humanos no âmbito de cada Estado, é a criação dos direitos do ser humano e de outros direitos básicos da sociedade em ordenamentos jurídicos específicos (CAVALCANTE, 2007, p.16).

A universalização dos Direitos fundamentais começa a ganhar notoriedade com a Declaração Universal dos Direitos do homem e do Cidadão de 1948, quando passou a obter contorno jurídico, a dignidade da pessoa humana - que é uma característica intrínseca ao homem para prática da sua liberdade e de direito relevantes para uma vida saudável e plena a qual pertencia a todo humano, não apenas aos franceses (BAHIA, 2017).

As dimensões dos direitos fundamentais fazem referências aos lemas da Revolução Francesa, Liberdade (primeira dimensão), Igualdade (segunda dimensão) e Fraternidade (terceira dimensão). Os direitos fundamentais de primeira geração são chamados de direitos da liberdade, pois se relacionam aos direitos civis e políticos que se opõem ao Estado. Esses direitos têm fundamento naturalista, isso porque, há uma consideração singular do homem, ou seja, tais direitos referem-se às liberdades públicas e aos direitos políticos, como direitos civis e políticos a traduzir o valor liberdade (LENZA, 2017).

No entendimento de Flávia Bahia (2017) os direitos de segunda geração, dizem respeito a uma proteção aos direitos sociais, econômicos e culturais, em que do Estado não mais se exige uma abstenção, mas, ao contrário, impõe-se a sua atuação positiva, a fim de fazer valer os direitos a igualdade. Ao contrário da dimensão anterior, os direitos de segunda geração são 
especialmente prestacionais, abrangendo maior intervenção estatal, em razão da evolução do Estado Liberal para o Estado Social.

Existe uma equivalência com os direitos sociais, culturais e econômicos, assim como os direitos coletivos e os da coletividade, os quais são mais benéficos a uma parcela da sociedade que ocupa posição menos privilegiada da estratificação social. (OLIVEIRA, 2006). Os direitos fundamentais de terceira geração foram marcados pela dinâmica da sociedade e por transformações na comunidade internacional. Isso porque, ao final da Segunda Guerra Mundial (1939-1945), as discussões acerca da própria compreensão do ser humano se modificaram, a sociedade passou a compreender a necessidade de se assegurar a proteção da dignidade da pessoa humana. Os direitos de terceira dimensão (solidariedade ou fraternidade) englobam, por exemplo, os direitos relacionados ao meio ambiente e à proteção jurídica do consumidor.

Para os defensores do direito de quarta dimensão, principalmente Bonavides, consiste em afirmar que é composta pelo direito à democracia direta, o direito a informação e o direito ao pluralismo (BONAVIDES, 2010). No que diz respeito a uma quinta geração do direito, Bonavides acredita que o direito à paz deveria ser tratado de forma independente, e que a paz é um postulado da democracia participativa, ou supremo direito da humanidade, o que constantemente vem sendo ameaçado, inclusive em decorrência de atentados terroristas como "11 de Setembro de 2001" e de grupo terroristas como Talibã, organização que atua no Afeganistão, e Estado Islâmico, ativo na Síria e no Iraque.

\subsection{O desenrolar da igualdade no ordenamento jurídico brasileiro.}

A Declaração dos Direitos do Homem e do Cidadão de 1948 ressaltou, no artigo $1^{\circ}$, que em princípio os homens nascem e permanecem iguais em direitos, concernindo à igualdade um dos lemas da Revolução Francesa de 1789. Além disso, a Constituição Federal de 1988 compõese de uma gama de valores fundamentais, dentre os quais o Princípio da Igualdade. Constatase no preâmbulo desta Carta, o qual é redigido pelo espírito da época, alusão ao princípio supracitado:

\footnotetext{
Nós, representantes do povo brasileiro, reunidos em Assembléia Nacional Constituinte para instituir um Estado democrático, destinado a assegurar o exercício dos direitos sociais e individuais, a liberdade, a segurança, o bem-estar, o desenvolvimento, A IGUALDADE e a justiça como valores supremos de uma sociedade fraterna, pluralista e SEM PRECONCEITOS, fundada na harmonia social e comprometida, na ordem interna e internacional, com a solução pacífica das controvérsias, promulgamos, sob a proteção de Deus, a seguinte Constituição da República Federativa do Brasil [grifo nosso].
} 
Ainda, identifica-se referência ao princípio no caput do Art. $5^{\circ}$ e no Inciso I do mesmo artigo da referida Carta, entretanto, não somente como princípio, e sim como direito e garantia fundamental, os quais devem ser obedecidos por todos:

Art. $5^{\circ}$ Todos são iguais perante a lei, sem distinção de qualquer natureza, garantindo-se aos brasileiros e estrangeiros residentes no País a inviolabilidade do direito à vida, à liberdade, à igualdade, à segurança e à propriedade, nos termos seguintes: I - homens e mulheres são iguais em direitos e obrigações, nos termos dessa Constituição [grifo nosso].

Por conseguinte, entende-se que a Constituição carrega em seu conteúdo um cuidado em obstruir as diversas espécies de discriminação, no entanto, fazendo-se uma leitura aos dispositivos, acredita-se que todos devem ser tratados de igual forma (LOFY, 2005).

A regra da igualdade não consiste senão em tratar desigualmente aos desiguais, na medida em que se desigualam. Nesta desigualdade social, proporcionada à desigualdade natural, é que se acha a verdadeira lei da igualdade. Os mais são desvarios da inveja, do orgulho, ou da loucura. Tratar com desigualdade a iguais, ou a desiguais com igualdade, seria desigualdade flagrante, e não igualdade real (BARBOSA, 2003, p.19).

Nessa perspectiva, o princípio da igualdade é uma forma de possibilitar que os valores de uma vida digna sejam enunciados em grau máximo, a fim de propiciar uma garantia individual e a eficácia de uma vida mais justa e humana.

\subsection{Direitos fundamentais à igualdade de gênero na sociedade brasileira}

Malgrado haja todo esse reconhecimento formal e material de direitos igualmente para todos, sem distinção de qualquer natureza, as mulheres ainda precisam reivindicar bastante para que esses dispositivos não venham apenas preencher material e formalmente o ordenamento jurídico, todavia, que venha preencher essencialmente com uma eficácia plena na sociedade, ou seja, igualdade de fato, de modo que sejam aplicados mecanismos e instrumentos alternativos a fim de garantir sua efetivação.

A Revolução Francesa de 1789 foi um marco de lutas para as mulheres, posto que essa época fez surgir uma reflexão acerca dos direitos representados pela Declaração dos Direitos do Homem e do Cidadão, do mesmo ano, os quais deveriam ser aplicados também às mulheres (OLIVEIRA, 2006).

No Brasil, antes da promulgação da Constituição de 1988, o papel da mulher era muito tímido. Cita-se como exemplo, o Código Civil de 1916, o qual trazia uma ideia patriarcal e 
machista, tendo em vista que esse código não concedia os mesmos direitos entre homens e mulheres. Em seu artigo 6 $6^{\circ}$, enxerga-se que há essa desigualdade: "São incapazes, relativamente a certos atos (art. 147, n. 1), ou à maneira de os exercer: II. As mulheres casadas, enquanto subsistir a sociedade conjugal".

Posteriormente, fatores como a urbanização e o crescimento da industrialização, foram cruciais para que as mulheres conseguissem ingressar no mercado de trabalho. No entanto, esse início foi marcado pelo preconceito e uma série de procedimentos que desvalorizavam cada vez mais o sexo feminino, verbi gratia, salários menores e nenhuma chance da mulher capacitar-se profissionalmente.

Hoje, analisando as mudanças que ocorreram durante esses séculos, avista-se que a luta do movimento feminista trouxe muitas conquistas para que as mulheres pudessem ocupar com mais autonomia e independência um lugar na sociedade.

\begin{abstract}
O movimento de mulheres exerceu papel fundamental nas conquistas históricas como no âmbito nacional em que, ocorreu o reconhecimento de igualdade entre homens e mulheres que, se torna obrigatório a partir da constituição de 1988 e mais atualmente a Lei Maria da Penha, e no internacional, a implantação do dia internacional da mulher que rememora a importância do movimento feminista, além de colocar na agenda pública a necessária atenção às políticas de gênero. (PEDRO e GUEDES, 2010, p. 8)
\end{abstract}

Sem embargo, apesar desse avanço, ainda tem-se o trabalho da mulher como um meio de força complementar de renda familiar, e por isso, a remuneração deve ser de "complemento" aos salários dos maridos.

É necessário que a própria mulher entenda a necessidade de separar casa e o trabalho ou até mesmo vida pública e privada, valorizando então sua participação constante no complemento da renda salarial familiar, inclusive, em muitos casos deixam de ser complementar para se tornarem a única renda que sua família tem mensalmente partindo do princípio de se analisar os grandes índices de abandono do lar por parte dos maridos e da falta de ensino e participação dos filhos em um mercado de trabalho, cada vez mais complexo para jovens que não tem experiência profissional. (BAYLÃO E SCHTTIONE, 2014, p. 5)

Além disso, muitas mulheres tiveram que reivindicar seus direitos, inclusive para ingressar em instituições de ensino, pois, anteriormente, era ideal que as mulheres tivessem uma educação doméstica a fim de melhor desenvolver seu papel na sociedade (OLIVEIRA, 2006).

Nessa perspectiva, o caminho que as mulheres conseguiram percorrer nos últimos séculos foi bem relevante: de uma educação doméstica, no período colonial, para uma participação mais tímida nas escolas públicas no século 19; em seguida um aparecimento na docência do ensino primário, e atualmente, uma frequência significativa em todos níveis de escolaridade. Conforme percebe-se no gráfico produzido pelo Instituto Brasileiro de Geografia e Estatística - IBGE: 
TABELA I - Nível de instrução da população de 25 anos ou mais, por sexo, período 2016.

Distribuição de percentual da população de 25 anos a 44

\begin{tabular}{|c|c|c|c|c|c|c|}
\hline \multirow{3}{*}{ Nível de instrução } & \multirow{2}{*}{\multicolumn{2}{|c|}{ Total }} & \multicolumn{4}{|c|}{ Sexo } \\
\hline & & & \multicolumn{2}{|c|}{ Homens } & \multicolumn{2}{|c|}{ Mulheres } \\
\hline & Proporção & $\mathrm{CV}(\%)$ & Proporção & $\mathrm{CV}(\%)$ & Proporção & $\mathrm{CV}(\%)$ \\
\hline Total & 100,0 & 0,0 & 100,0 & 0,0 & 100,0 & 0,0 \\
\hline $\begin{array}{l}\text { Sem instrução e ensino } \\
\text { fundamental incompleto }\end{array}$ & 26,3 & 0,8 & 29,7 & 0,9 & 23,0 & 1,0 \\
\hline $\begin{array}{l}\text { Ensino fundamental } \\
\text { incompleto e ensino } \\
\text { médio incompleto }\end{array}$ & 14,9 & 1,0 & 15,6 & 1,3 & 14,2 & 1,2 \\
\hline $\begin{array}{l}\text { Ensino médio completo e } \\
\text { superior incompleto }\end{array}$ & 40,3 & 0,6 & 39,2 & 0,8 & 41,3 & 0,7 \\
\hline Ensino superior completo & 18,6 & 1,7 & 15,6 & 2,2 & 21,5 & 1,6 \\
\hline
\end{tabular}

Fonte: IBGE. Pesquisa Nacional por Amostra de Domicílios Contínua, 2016, segundo trimestre. [elaboração pelos autores]

Observando-se, vê-se que o fato das mulheres apresentarem um maior nível de instrução não impacta de forma positiva a posição no mercado de trabalho. Isso porque, as mulheres ainda percebem menos que os homens em inúmeros níveis de escolaridade. Quando se fala em vida social, o trabalho é uma dimensão muito importante para o indivíduo e a coletividade, tanto no que se refere à produção de bens e serviços, quanto à realização individual de um humano, o qual possibilita que o indivíduo obtenha recursos financeiros para conquistar uma maior qualidade de vida.

Consoante a Pinheiro et al (2016), no Brasil, avistando-se em sua cultura toda essa segregação de grupos sociais mais abastados em detrimento de grupos de indivíduos mais necessitados, os diversos contextos de trabalhos continuam engessados em uma desigualdade de gênero e de raça. Dessa forma, infere-se que a Educação não é apenas o único foco do governo para atenuar a desigualdade de gênero nas diversas esferas que envolvem esse tema, sendo imprescindíveis políticas públicas para se evitar esse nível de contraste entre homens e mulheres. 


\section{AS FEIRAS MÓVEIS}

A feira móvel tem como característica uma aglomeração de pessoas em um lugar específico para executar trocas e vendas de mercadorias. Acredita-se que desde a Antiguidade, nos primeiros conglomerados humano, as feiras livres dispuseram de grande relevância no que tange ao reconhecimento da atividade do comercio nas cidades, vilas e aldeias.

Foi a partir do excedente da agricultura, na Idade Média, que houve a possibilidade das primeiras formas de troca e de comercialização de mercadorias que ocorriam nas frentes dos castelos. No Brasil, as feiras começam a ganhar destaque com a chegada da família real em 1808, e a partir da abertura dos portos para as nações amigas que as feiras livres se beneficiaram ganhando maior notoriedade (GOMES et al, 2013).

O Comércio de feira, para Sá (2010), é atualmente uma atividade econômica de grande relevância para a população brasileira, particularmente para o povo Nordestino, o qual há uma parcela considerável que possui o hábito semanal de realizar compras nesses lugares. Nessa perspectiva, as feiras livres propiciam relações econômicas, sociais e culturais, firmando assim, um espaço democrático e característico da região, mesmo que estejam sendo obrigadas a se adaptar aos processos técnico-científicos e informacional, observado tanto nas grandes empresas como nas pequenas organizações informais.

\subsection{As feiras móveis dos bairros da Cidade 2000 e da Praia do Futuro}

As feiras escolhidas para campo de pesquisa apresentam características não diferentes das demais feiras livres do Brasil. Devido ao crescimento acelerado de Fortaleza e ao excedente elevado de trabalhadores, o setor informal da economia tornou-se a opção de muitos indivíduos em busca da sobrevivência. Sua organização pode-se comparar com o surgimento do direito comercial o qual tinha características corporativistas onde os comerciantes criavam regras para serem cumpridas entre eles (RAMOS, 2017). Assim, os próprios feirantes são responsáveis pela definição de horários de montagem e desmontagem das bancas até definição da faixa de preços praticados. Segundo Sato (2007), eles constroem entre si regras de convivência específica, em geral válidas apenas para os feirantes que as definem, sendo impraticável qualquer tentativa de generalização.

Observa-se que a instalação provisória das bancas ou barracas das feiras, gera uma série de problemas que afetam diretamente aos feirantes e aos consumidores, como a falta de 
banheiros e de segurança pública.

FOTOGRAFIAS I - Feira da Cidade 2000 e Praia do Futuro.
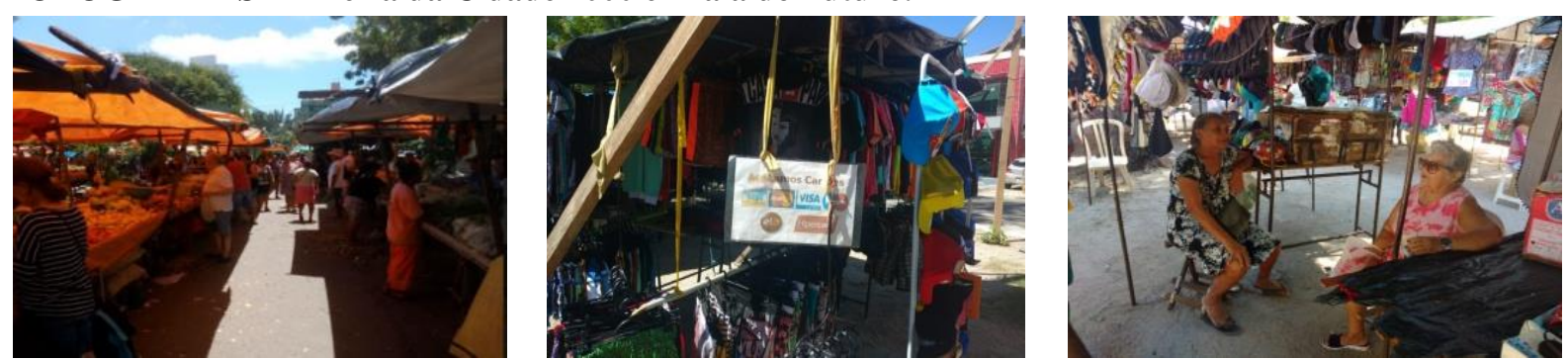

Fonte: Própria, autorizado pelos feirantes, 2018

Apesar desse ambiente com traços tumultuados, as feiras, que estão em locais estratégicos de cada bairro ou cidade, começam suas atividades em um horário relativamente cedo em comparação ao comércio composto por lojas físicas, devido ao grande número de consumidores, que em sua maioria, escolhem a compra dos produtos na feira pelo preço abaixo em relação aos supermercados e lojas, bem como a possibilidade de negociação.

No que se refere à perspectiva cultural, "a feira livre é uma importante instituição que resguarda tradições, indiferente, inclusive, ao processo de modernização" (LEAL et al, 2015. p. 4) . Dessa forma, cria um elo entre a vida urbana e a rural, as quais são caracterizadas com seus diferentes valores e hábitos.

\section{MATERIAIS E MÉTODOS}

Foi utilizada a pesquisa bibliográfica baseada em livros, artigos científicos, doutrina e legislação vigente acerca do princípio da igualdade de gênero. Como afirma Gil (2008), a vantagem desse tipo de estudo fundamenta-se "no fato de permitir ao investigador a cobertura de uma gama de fenômenos muito mais ampla do que aquela que poderia pesquisar diretamente".

O trabalho baseia-se também em fontes de dados primários, as quais são extraídas por meio de uma conversa informal, incluindo comerciantes e funcionários. Logo após, utilizou-se do estudo etnográfico - o qual apresenta como objeto a análise da hierarquia estratificada de estruturas significantes (GEERTZ, 1989). Esse tipo de estudo possibilita que as diversas ações dos feirantes sejam identificadas e interpretadas, como ilustra Geertz (1989), uma descrição densa viabiliza diferenciar um tique nervoso e uma piscadela comum utilizada para se comunicar.

As feiras móveis foram o campo empírico da pesquisa, que ocorrem semanalmente na 
Praia do futuro e na Cidade 2000, em Fortaleza, objetivando, por meio de uma observação participante, compreender e apresentar a visão nativa dos feirantes consoante a sua realidade de trabalho.

(...) a observação participante consiste na participação real do conhecimento na vida da comunidade, do grupo ou de uma situação determinada. Neste caso, o observador assume, pelo menos até certo ponto, o papel de um membro do grupo. Daí por que se pode definir observação participante como a técnica pela qual se chega ao conhecimento da vida de um grupo a partir do interior dele mesmo (GIL, 2009, p. 103)

Utiliza-se o mesmo sentido de Malinowski quanto ao entendimento sobre o objetivo da visão nativa, que consoante a ele:

\begin{abstract}
"[...] esse objetivo é de apreender o ponto de vista dos nativos, seu relacionamento com a vida, sua visão de seu mundo. É nossa tarefa estudar o homem e devemos, portanto, estudar tudo aquilo que mais intimamente lhe diz respeito, ou seja, o domínio que a vida exerce sobre ele. Cada cultura possui seus próprios valores; as pessoas têm suas próprias ambições, seguem a seus próprios impulsos, desejam formas de felicidade. Em cada cultura encontramos instituições diferentes, nas quais o homem busca seu próprio interesse vital; costumes diferentes, nas quais ele satisfaz às suas aspirações; diferentes códigos de lei e moralidade que premiam suas virtudes ou punem seus defeitos. ”(MALINOWSKI, 1978, p. 33)
\end{abstract}

Vale salientar que a metodologia utilizada possibilita fazer apenas a apresentação do conteúdo extraído da vivência do pesquisador com a realidade em campo. Para isso, foram realizadas visitas à feira móvel semanalmente durante 4 (quatro) meses no ano de 2019. Além de conversas com 40 (quarenta) feirantes para compreender sua realidade na feira móvel e a sua visão no que diz respeito à efetivação dos direitos fundamentais à igualdade de gênero nas relações de trabalho no que tange às atividades exercidas entre homens e mulheres.

\title{
5 RESULTADOS E DISCUSSÕES
}

Em diálogos informais realizados com 40 feirantes, sendo 24 homens e 16 mulheres, analisou-se as suas narrativas acerca dos direitos fundamentais à igualdade de gênero, traçandose um paralelo sobre sua visão e a aplicabilidade das concepções jurídicas na realidade do campo de pesquisa. Para tal, foram analisados os seguintes aspectos: a) nível de conhecimento sobre os direitos fundamentais; b) o princípio da igualdade de gênero na realidade das feiras; c) diferença salarial entre homens e mulheres; d) a capacidade das mulheres em gerir negócios.

Todos os setores apresentam trabalhadores do sexo masculino e feminino. No entanto, no setor alimentício (frutas, verduras, carnes etc.), o número de homens é consideravelmente maior. Segundo relatos, esse setor exige uma maior capacidade física, pois há um volume intenso de caixas com mercadorias que precisam ser descarregadas dos caminhões, sendo um 
dos principais motivos da ausência das mulheres nesse ramo, como pode ser avistado no relato de um feirante do sexo masculino: "o trabalho no setor de frutas é pesado, a mulher não tem força para descarregar o caminhão, é pesado, não tem condições. 'Tem que ter mais rapidez', chega tarde, tem que acordar 2 horas da manhã para ir a Ceasa, aí não tem condições de contratar uma mulher".

Além disso, alega-se o fato de que nesse setor é necessária maior disposição, tendo em vista que é preciso ir à Ceasa retirar a mercadoria. Entretanto, o depoimento de uma feirante que atua em ramo semelhante, demonstrou possuir capacidade física para exercer suas atividades, alegando não ser um entrave o seu gênero feminino. Muitos dos depoimentos ficam em contraste com o princípio da igualdade de gênero, mostrando-se haver um pensamento conservador acerca da impossibilidade do trabalho da mulher ser realizado em atividades que requerem esforço físico.

Ainda, conforme depoimentos de feirantes, verificou-se que nas feiras móveis predomina o machismo, tornando-se mais difícil a oportunidade de mulheres atuarem no setor mais rentável, que é o de frutas. Tais afirmações podem verificadas no depoimento de um feirante do setor de frutas, graduado em Pedagogia: “O ambiente de feira é muito machista, é um local que você está exposto a tudo, não tem estrutura, por exemplo, pra mulher, não tem um banheiro, não tem banheiro público em feira nenhuma aqui em Fortaleza, não tem! Não está muito relacionado ao trabalho, e sim pelo fato de não ter estrutura” afirma.

No que tange à realidade das feiras, há depoimentos bem divergentes acerca da satisfação na realização de suas atividades, pois há tanto feirantes que dizem gostar de trabalhar com o público, quanto feirantes que não se sentem satisfeitos, pois estão naquela realidade por falta de outras oportunidades de trabalho. Notam-se esses fatos no relato de M., sexo feminino, 55 anos, “O movimento da feira está fraco. Só está dando para se manter. Só fico aqui porque não há outra opção. As vendas estão fracas por conta do local que tem muita poeira e muitos clientes tem asma. A gente mesmo está ficando doente por causa dessa poeira fina”. Além desses problemas, vários outros são citados constantemente nas conversas, como a falta de segurança pública, uma estrutura adequada com banheiros etc., os quais dificultam muito, segundo eles, para as mulheres e crianças.

Nesse sentido, avista-se a ineficácia no que diz respeito aos direitos e garantias fundamentais, pois conforme demonstram os depoimentos, há um desrespeito com os feirantes quanto à aplicabilidade do capítulo II "dos direitos sociais" da $\mathrm{CF} / 88$, notadamente quanto à 
valorização do trabalho. Diante disso, a eficácia de uma realidade de trabalho propícia à saúde e segurança do trabalhador compete ao Estado e ao Município, mediante a uma legislação eficaz e por meio de medidas alternativas, como de higiene e segurança, as quais sejam plenamente efetivas no contexto de trabalho dos feirantes.

Ainda, acerca dos direitos fundamentais, dando ênfase à igualdade de gênero, 14 (quatorze) feirantes disseram que já ouviram falar, mas não souberam exemplificar e discorrer sobre algum direito fundamental. Os que disseram saber dos seus direitos, 6 (seis) souberam falar de algum tipo de direito, tais como a liberdade, a vida, o trabalho, dentre outros. Um dos depoentes, 45 anos, sexo feminino, proprietária de uma barraca de carregadores de celular citou os direitos de ir e vir, à saúde, à educação e de votar. Outros cinco feirantes citaram seus direitos como trabalhadores, art. $7 \mathrm{da} C F / 88$, e afirmaram pagar o INSS para terem direito à aposentadoria e auxílio doença, caso precisassem. Porém, os demais feirantes alegaram não saber do que se tratava a pergunta.

No que diz respeito à igualdade de gênero constatou-se diversas contradições. Muitos feirantes, inclusive mulheres tiveram dificuldade em compreender e argumentar sobre a questão. A maioria dos feirantes entrevistados afirmou não haver diferença entre homens e mulheres, existindo uma igualdade, no entanto, ao ser indagado em relação a muitas mulheres trabalharem em iguais atividades com diferença salarial, como foi demonstrado pelo estudo de BRASILEIRO (2017), justificou que esse preconceito é algo enraizado e que existe em outros âmbitos da sociedade, apesar de não concordarem.

\section{CONSIDERAÇÕES FINAIS}

Compreender a visão nativa dos feirantes permite descobrir o grau de eficácia dos direitos fundamentais à igualdade de gênero na feira móvel e suas principais necessidades no que diz respeitos aos direitos fundamentais garantidos na Constituição Federal de 1988. Os depoimentos analisados mostram que os feirantes possuem uma visão conservadora quanto ao princípio da igualdade de gênero, tendo em vista que eles se limitam apenas a descrever o tipo de trabalho exercido por homens e mulheres, acreditando haver a igualdade de gênero nas relações de trabalho, não se referindo à capacidade das mulheres em gerir negócios e atuarem em atividades que necessitem de maior esforço físico.

É perceptível pelos depoimentos descritos, relativos à situação das mulheres feirantes em Fortaleza, que o princípio da igualdade de gênero entre homens e mulheres carece de 
efetividade, isto é, as diferenças existentes em termos de acesso, constatadas nesta pesquisa pela reduzida taxa de participação de mulheres nas feiras e, ainda, a diferença salarial para trabalhos iguais conforme estudos anteriores (BRASILEIRO, 2018), em contraste com a taxa de escolaridade das mulheres superior a dos homens, consoante a Tabela 1 presente no desenvolvimento, não deixam margem de dúvidas quanto às desigualdades existentes em função de gênero.

Nessa lógica, posto que haja essa dificuldade no acesso ao trabalho nas feiras é que se entende a necessidade do Estado e do Município buscarem alternativas a fim de coibir as práticas de discriminação por motivo de gênero na feira móvel em Fortaleza. Isso porque, esses entes federativos têm o direito de zelar pela guarda da Constituição e das instituições democráticas, bem como a efetivação do princípio da igualdade de gênero, por meio da igualdade de oportunidade de trabalho e de um ambiente digno de trabalho, ou seja, uma realidade adequada ao trabalho humano, principalmente ao trabalho da mulher feirante, pois como consta nos relatos supramencionados, o ambiente insalubre da feira é um dos quesitos que distância e alimenta a discriminação no que diz respeito ao homem e à mulher.

No mais, esse estudo não tem a intenção de esgotar a temática, mas visa contribuir para que outras pesquisas sejam realizadas a fim de permitir a efetivação dos direitos fundamentais à igualdade de gênero, bem como a aplicação da pesquisa em feiras localizadas em outros estados a fim de propiciar análises e comparações e, assim, disseminar a problemática do tema, projetando-se para erradicação da discriminação em função de gênero.

\section{REFERÊNCIAS}

BAHIA, Flavia. Coleção Descomplicando: Direito Constitucional. 3 ed. Recife: Armador, 2017.

BARBOSA, Rui apud LOFY, William. A ação afirmativa e o respeito aos princípios da Igualdade e Dignidade da Pessoa Humana. DireitoNet, São Paulo, 03 mai. 2005. Disponível em: <http://www.direitonet.com.br/artigos/x/20/24/2024/>. Acesso em: 10 ago. 2018.

BAYLÃO, A. L. S.; SCHETTINO, E. M. O. A Inserção da Mulher no Mercado de Trabalho Brasileiro. In: Simpósio de Excelência em Gestão e Tecnologia, 11., 2014, Rio de Janeiro. Anais eletrônicos. Disponível em: <https://www.aedb.br/seget/arquivos/artigos 14/20320175.pdf> . Acesso em: 20 ago. 2018

BONAVIDES, Paulo. Curso de Direito Constitucional. 26 ed. São Paulo: Malheiros, 2010.

BRASIL. Constituição da República Federativa do Brasil: promulgada em 5 de outubro de 1988. 24. ed. atual. e amp. São Paulo: Saraiva, 2002 
BRASILEIRO, C. T. T; CAVALCANTE, L. C. Eficácia dos direitos fundamentais e trabalho digno nas feiras móveis. Extensão em Ação, Fortaleza, v. 1 , n. 15, janeiro-junho 2018.

CAVALCANTE, L. C. O princípio constitucional da dignidade da pessoa humana como fundamento da produção da existência em todas as suas formas. Dissertação Mestrado em Direito Constitucional. Unifor - 2007.

GEERTZ, C. Uma descrição densa: por uma teoria interpretativa da cultura. In: A interpretação das culturas. Rio de Janeiro: LTC, 1989.

GIL, A. C. Métodos e técnicas de pesquisa social. 6. ed. São Paulo: Atlas, 2008

GOMES, A. F.; SILVA, J. S. F.; SANTOS, A. A.; SANTANA, W. G. P.; SANTOS, J. A. G. Perfil socioeconômico de mulheres feirantes : um estudo no interior baiano. In: IV Encontro de Administração Política. 4. Anais. Salavador: EAP, 2013.

LEAL, L. E. B. B.; SILVA, N. A. N.; BERTOLAZO, I. N. Da banana ao pão: um estudo sobre mulheres feirantes e empreendedorismo. In: Simpósio Internacional de Gestão de Projetos, Inovação e Sustentabilidade. São Paulo, 2015. Anais do IV SINGEP. São Paulo:UNINOVE, 2015.

LENZA, Pedro. Direito Constitucional esquematizado. 21 ed. São Paulo: Saraiva, 2017.

LOFY, Willian. A Ação Afirmativa e o respeito aos princípios de Igualdade e Dignidade da Pessoa Humana. DireitoNet, São Paula, 03 mai. 2005. Disponível em:

$<$ https://www.direitonet.com.br/artigos/exibir/2024/A-Acao-Afirmativa-e-o-respeito-aosprincipios-de-Igualdade-e-Dignidade-da-Pessoa-Humana > Acesso em 08 ago. 2018.

MALINOWSKI, Bronislaw Kasper. Argonautas do Pacífico Ocidental: Um Relato do Empreendimento e da Aventura dos Nativos nos Arquipélagos da Nova Guiné Melanésia. São Paulo, Abril Cultural, 1978.

OLIVEIRA, Daniely Rodrigues de. O Direito fundamental à igualdade de gênero na Constituição brasileira de 1988. Monografia Bacharel em Direito. UFC - 2006.

PEDRO, C. B.; GUEDES, O. de S. As conquistas do movimento feminista como expressão do protagonismo social das mulheres. In: Simpósio sobre Estudos de Gêneros e Políticas Públicas, 1., 2010, Paraná. Anais. Paraná: UEL, 2010. p. 1-10.

PINHEIRO, L. S.; JUNIOR, A. T. L.; FONTOURA, N. O.; DA SILVA, R. Mulheres e trabalho: breve análise do período 2004-2014. Nota Técnica. Brasília: IPEA, 2016.

RAMOS, André Luiz Santa Cruz. Direito empresarial. 7. ed. São Paulo: Método, 2017. 933 p.

SÁ, M. G.. Feirantes: Quem são? como administram seus negócios?. In: Encontro ANPAD. 34. Anais. Rio de Janeior: Enanpad, 2010. 
SATO, Leny. Processos cotidianos de organização do trabalho na feira livre. Psicol. Soc., Porto Alegre, v. 19, n. spe, p. 95-102, 2007 . Disponível em

$<$ http://www.scielo.br/scielo.php?script=sci_arttext\&pid=S010271822007000400013\&lng=pt \&nrm=iso $>$. Acesso em 12 ago. 2018.

SEGUNDO, Hugo Machado. FUNDAMENTOS DO ORDENAMENTO JURÍDICO Liberdade, igualdade e democracia como premissas necessárias à aproximação de uma justiça possível. Tese de Doutorado, 2009. 